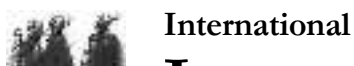 \\ Journal of Human Sciences \\ ISSN:2458-9489
}

Volume 17 Issue 4 Year: 2020

\section{Importance of play therapy in social work practice with children}

\section{Çocuklarla sosyal hizmet uygulamasinda oyun terapisinin önemi}

\author{
Esra Kılıç Ceyhan ${ }^{1}$
}

\begin{abstract}
If we can find ways to hear and understand children, they have a lot to say, tell and teach us, adults. Children who do not have extensive verbal abilities like adults can express themselves through playing. It has been proven by research that the best method by which they can convey their feelings, thoughts and problems is play therapy. At this point, it is important that professionals working with children are equipped with the knowledge of play therapy. Social workers who frequently come into contact with children in their professional lives should be involved in the field as play therapy practitioners. However, when the literature is examined, it is seen that there are very few practices and studies on the subject in Turkey. This study presents the place and importance of play therapy in social work practice with children in the light of the researches and applications in the literature, and highlights the importance of the use of play therapy as a method by social workers working with children. It has been observed that play therapy needs a wider coverage in social work practice and research. Suggestions have been made for popularizing play therapy in the relevant social work education, research and practices.
\end{abstract}

Keywords: Working with children, social work, play, play therapy.

(Extended English summary is at the end of this document)

\section{Özet}

Çocukları duymaya, anlamaya ilişkin yollar bulanabilirse, onların yetişkinlere söyleyecekleri, anlatacakları, öğretecekleri çok şey vardır. Yetişkinler gibi geniş sözel yeteneklere sahip olmayan çocuklar kendilerini oyun yoluyla ifade edebilmektedirler. Onların duyguların, düşüncelerini, sorunlarını aktarabilecekleri en iyi yöntemin oyun terapisi olduğu araştırmalarla kanıtlanmıştır. $\mathrm{Bu}$ noktada çocuklarla çalışan profesyonellerin oyun terapisiyle ilgili bir donanıma sahip olması önem arz etmektedir. Mesleki yaşamlarında sıkça çocuklara temas eden sosyal hizmet uzmanlar1, oyun terapisi uygulayıcisı olarak alanda yer almalıdır. Ancak alan yazın incelendiğinde konuyla ilgili ülkemizdeki uygulama ve çalışmaların çok az sayıda olduğu görülmüştür. Çocuklarla sosyal hizmet uygulamasinda oyun terapisinin yeri ve öneminin literatürdeki araştırmalar ve uygulamalar 1şığında sunulduğu bu çalışmada, çocuklarla çalışan sosyal hizmet uzmanlarının oyun terapisini bir yöntem olarak kullanmalarının önemine dikkat çekilmiştir. Oyun terapisinin sosyal hizmet uygulama ve araştırmalarında daha geniş yer almaya ihtiyacı olduğu görülmüsstür. Konuyla ilgili sosyal hizmet eğitim, araştırma ve uygulamalarında oyun terapisinin yaygınlaştırılması için önerilerde bulunulmuştur.

Anahtar Kelimeler: Çocuklarla çalışma, çocuklarla sosyal hizmet, oyun, oyun terapisi.

\footnotetext{
1 Assist. Prof., Ankara Yildırım Beyazıt University, Faculty of Health Sciences, Social Work Department, ekilic@ybu.edu.tr (iD) Orcid ID: 0000-0002-9853-5788
} 


\section{Giriş}

İnsanların iyilik durumlarının ve işlevselliklerinin artırlmasını amaçlayan sosyal hizmet mesleği ve disiplini, bireye ve bireyin çevresi ile etkileşim noktalarına müdahale ederek ve sosyal değişimi destekleyerek (IFSW, 2014) çocuk, ergen, engelli, yaşlı, hasta, suçlu vb. birçok müracaatçı grubuna yönelik mesleki faaliyetler sunmaktadır. Her bir müracaatçı grubunun kendine özgü değeri olmakla birlikte sosyal hizmet uzmanlarının en yoğun ve hassas faaliyet alanını çocuklar oluşturmaktadır. Çocuklar, başta ailede olmak üzere okulda, adliyede, çocuk refah kurumlarında, rehabilitasyon merkezlerinde, göçmen kamplarında, vb. birçok alanda, uzmanların müdahale alanına dahil olmaktadırlar.

Bu noktada çocuklarla iletişim sağlamanın yetişkinlerle çalışmadan farklı özel bilgi ve beceriler gerektirdiği bilinmelidir. Alan yazın incelendiğinde görülmektedir ki oyun, çocukla bağ kurmanın en etkili yoludur. Çocuklar, oyun yoluyla duygularını, düşüncelerini ifade edebilirler. Erik Erikson oyunun, çocukluktaki en doğal kendini iyileştirme süreci olduğunu belirtir (https://www.thekidstherapycenter.com/about-us.). Tipk1 yetişkinlerin duygu ve düşüncelerini sözel olarak ifade ettikleri gibi firsat verildiğinde çocuklar da duygu ve ihtiyaçlarını oynayarak ifade edeceklerdir (Öğretir, 2008). Dolayısıyla çocukla mesleki ilişki kurma, sürdürme ve ona yardım etme süreci oyun terapisi bilgi ve becerisini gerektirir.

Oyun terapisi, çocuğun duygu, düşünce ve sorunlarını oyun ve oyuncaklar aracıllı̆̆ıyla aktardığ1, bu konuda teorik ve süpervizyon eğitimlerini tamamlamış profesyoneller tarafindan sunulan bir terapi çeşididir (Landreth, 2002). Oyun terapisi yaklaşımlarını kullanarak çocukla çalışmanın, sosyal hizmet uzmanlarının sahip olması gereken becerilerden biri olduğu belirtilmektedir (Center For Clinical Social Work, 2007; G. Cooper \& Granucci Lesser, 2011). Oyun terapisi, etkililiği araştırmalarla kanıtlanmış temellere dayanması bakımından çalışmalarında kanıta dayalı uygulamaları benimseyen uzmanlar için büyük önem taşımaktadır (Weil, 2012). Mesleki çalışmalarında çocuklarla sık sık bir araya gelen uzmanların oyunun gücünü kullanabilmek adına oyun terapisiyle ilgili donanıma sahip olmalarının gerekliliği bilinen bir gerçek iken; mevcut durumda uzmanların bu konuyla ilgili bilgilerinin, becerilerinin, oyun terapisini uygulamalarında kullanma oranlarının araştırılmaya değer bir konu olduğu düşünülmektedir. Konuyla ilgili bu makalede alan yazındaki araştırmalar ve uygulamalar doğrultusunda bir derleme yapılmıştır.

$\mathrm{Bu}$ çalışma, çocuklarla sosyal hizmet uygulamasında oyun terapisinin önemine dikkat çekmek amacıyla hazırlanmıştır. Alan yazın incelendiğinde konuyla ilgili az çalışmaya rastlanmıştır. $\mathrm{Bu}$ derlemenin çocuk alanında çalışan uzmanlara oyun terapisiyle ilgili farkındalık sağlamada etkili olacağ1 ve literatüre katkı sağlayacağı düşünülmektedir. Ayrıca, konuyla ilgili alanda yapılacak gelecek çalışmalara da ışık tutması beklenmektedir.

\section{Oyun Terapisi}

Oyun terapisi, çocuğun kendini ifade etmesinin doğal bir yoludur. Çocuklar genellikle deneyimlerini veya nasıl hissettiklerini ifade edecek kelimelerden yoksundurlar. Tipkı birçok yetişkin terapi türünde kişinin yaşadığı zorlukları "konuşarak" anlatması gibi çocuklarda duygu ve sorunlarını "oynayarak" ifade ederler (Axline, 2019: 20). Böylece oyun terapisi seansları sırasında duygularını oyun yoluyla ortaya koyarlar, bu da iç dünyalarında neler olup bittiğini anlamaya yardımcı olur.

Landreth (2002)'e göre oyun, çocuğun dili; oyuncaklar ise çocuğun kelimeleridir. Axline (2019), bir çocuğun oyuncakları kullanarak kendi dünyasını düzenleyebileceğini ileri sürmüştür; oyuncaklarla oyun oynarken çocuklar sevgi, öfke, üzüntü, korku ve neşe gibi bir dizi duygu yaşarlar ve oyun terapisi bu duygularını serbest bırakmak için onlara olanak sağlar. Bütün gününü yapılandırılmış ortamlarda belli kurallara uymaya çalışarak geçiren çocuklar için oyun terapisi odası enerjilerini salacakları güvenli bir terapötik ortam oluşturur (Ray, 2019: 40).Ünlü filozof JeanJacques Rousseau, çocukların takdir edilmeye, ilgilenilmeye ve yetişkin gözetiminin az miktarda olduğu bir ortamda doğal hareket etmeye ihtiyaçlarının olduğunu düşünmüştür (Ray, 2019: 24).

Landerth, optimal büyüme ve gelişme için çocuğun doğal iletişim aracı olan oyun yoluyla duygu, düşünce, davranış ve deneyimlerinin keşfedilebileceğini ifade eder. Oyun terapisi sürecinde, çocuğun kendisini tam olarak ifade etmesi için sağlanan oyun materyalleriyle, oyun terapisi 
yöntemleri konusunda eğitilmiş terapistlerle çocuklar arasındaki dinamik kişilerarası güvenli bir ilişki geliştirildiğini belirtmektedir (Landreth, 2002; 16). Oyun terapisinin en güçlü yönlerinden biri, bir oyun yöntemi olmasıdır. Nash ve Schaeffer (2010)' e göre çocukların oyun oynama konusundaki doğal istekleri nedeniyle, oyun terapisi, terapistlerin çocuklarla gelişimsel düzeylerine uygun iletissim kurmalarına yardımcı olmaları ve olumlu bir terapötik bağ kurmaları için en iyi yöntemi sunar (Akt: Weil, 2012).

Nash ve Schaefer (2017) çocuk için oyunun faydalarını şu şekilde açılar: "Oyun; eğlencelidir, yaratıcıdır, stresi hafifletir, hayal kurmayı sağlar, özgüven ve sorumluluk duygusunu destekler, olumlu sosyal etkileşimi ve iletişimi teşvik eder. Çocuklar, oyun oynarken engellenmelere katlanmayı, duygularını düzenlemeyi, gelişimsel görevlerde başarılı olmayı öğrenir ve yeni beceriler kazanır." Çocuklar oyunları sırasında kendileri için önemli sahneleri canlandırabilir, belirli sorunları çözebilir veya duygularını paylaşan karakterler yaratabilirler. Kısaca çocuklar oyun yoluyla hayatı prova eder.

Oyun terapisi için kullanılan malzemeler; oyuncak bebek, evcilik oyuncakları, hayvanlar, kuklalar, kum, su, kil, oyun hamuru, legolar, arabalar, doktor seti, sanat-çizim malzemeleri, kart, masa oyunları vb. şeklinde sıralanmaktadır (Axline, 2019: 77). Oyun terapi odası belli kriterlere göre bahsedilen oyuncaklarla donatılmış şekilde tasarlanmalıdır. Bazı durumlarda okulda, hastane ortamında, vb. yerlerde de oyun terapisi yapılmasının yolları söz konusudur. Bunun için oyun terapisi yapılacak ortamların düzenlenmesi ve oyun materyallerinin bulunduğu bir çantanın hazırlanması önerilmektedir

\section{Oyun Terapisi Çeşitleri}

Oyun terapisi uygulamaları, farklı kuramlar ışığında gerçekleşmeleri ve yöntemlerindeki farklılıklardan dolayı çeşitli şekillerde gerçekleşmektedir. Özünde her birinin amacı çocuğu anlamak ve ona yardım etmek olan oyun terapisinin sık kullanılan ve araştırmalarla etkililiği kanıtlanmış bazı türleri şu şekildedir:

Cocuk merkezli oyun terapisi: Axline tarafindan Carl Rogers'in 'birey merkezli oyun terapisi' temel alınarak geliştirilmiştir (Axline, 2019: 21). Axline, "çocuklar hakkındaki bilginin en iyi kaynağ1 çocuklardır" anlayışıyla hareket etmiş ve çocukların hem sorunlarını dile getirmede hem de çözüm üretmede sonsuz bir potansiyele sahip olduklarını vurgulamıştır. Bu anlayışla; oyun terapisti bir tanı koyucu ya da terapötik direktör değildir; aksine kendini keşfetme amaçlı bir yolculukta çocuk için bir kolaylaştırıcı ve keşif arkadaşıdır. Axline, 1964'te bu doğrultuda bir çocuk danışanıyla gerçekleştirdiği oyun terapisi uygulamasını günümüzde Türkçe'ye de çevrilmiş olan "Benliğini Arayan Çocuk" kitabında paylaşmıştır (Axline, 2018). Kitap, gerçek bir vaka çalışması olması itibariyle oyun terapisinin önemini ortaya koymaktadır. Zekâ geriliği olduğu düşünülen, içine kapanık ve iletişim kuramayan bir çocuğun, oyun terapisinin sağladığı ortamla benliğini ve yeteneklerini keşfettiği, çeşitli duygularına doğru yolculuğa çıktığı bir süreci anlatmaktadır.

Deneyimsel Oyun Terapisi: ABD'li profesörler Byron ve Carol Norton tarafindan geliştirilmiş olan deneyimsel oyun terapisi, 25 yllı aşkın çalışmalarla etkinliği kanıtlanmış bir oyun terapisi yöntemidir. Deneyimsel Oyun Terapisinde çocuğun oyunun yöneticisi olmasına izin verilir (Norton \& Norton, 2017: 187). Çocuklar, deneyimsel oyun terapisi sırasında, terapist desteği içinde ancak terapisti kendisinin yönlendirdiği bir süreçte, duygusal deneyimleri üzerinde çalışmaktadır. Çocukların kendilerine özgü bakış açıları dikkate alınır ve çocuk farklı, kendine has bir birey olarak değerlendirilir.

Bilişsel Davranışı Oyun Terapisi: Problem/amaç merkezli, süre sınırlaması olan, kısa, yönlendirici, yapılandırılmış ve psikoeğitimsel bir oyun terapisi yöntemidir (Knell, 2017:316).Yönlendirici olmayan oyun terapisinde (yukarıda açılanan iki oyun terapisi türünde olduğu gibi) terapist, terapiyi çocuğun önderliğinde sürdürürken; bilişsel davranışçı oyun terapisinde terapist yönlendirme yapar, amaçları belirler ve bu amaçlara uygun müdahaleler geliştirir. Bilişsel davranış̧̧ oyun terapisinde terapist, çocukla birlikte etkinlikleri seçer ve tedaviye psikoeğitimsel bir bileşen katar. Oyunu eğitici bir araç olarak kullanır ve çocuğun duygu, düşünce ve davranışları arasındaki bağlantıları keşfetmesini sağlar. 
Filial Terapi: 'Aile terapisi' ve 'oyun terapisi’ yaklaşımlarının bütünleştiği bir oyun terapisi yaklaşımı olan filial terapide; hem çocuğun sorun ve kaygılarına hem de aile içi sorunların çözümüne yardımcı olmaya çalışlır. Terapist, ebeveynlere çocukları ile özel ve yönlendirme yapmaksızın oyun seanslar1 yürütmeleri konusunda eğitim ve süpervizyon verir (Topham ve VanFleet, 2011). Ebeveynler, özel oyun zamanlarını yürütmede yeterli ve güvenli hale geldikçe bunlanı ev ortamına taşırlar; terapistte ilerlemeyi izlemeye devam eder. Filial oyun terapisinin koruyucu aile yanında ya da evlat edinilmiş ailelerde, yüksek düzeyde travmatize olmuş ve bağlanma bozukluğu olan çocuklarda etkililiği kanıtlanmıştır (Rennie ve Landreth, 2000).

\section{Sosyal Hizmet Uzmanlanının Oyun Terapisi Uygulamalanı}

Oyun terapisi pratikte çok uygulansa da; konuyla ilgili araştırma ve yayın boyutundaki çalışmalar zayıf kalmıştır (Bratton ve diğ., 2005). Özellikle alan yazına bakıldığında sosyal hizmet uzmanlarının oyun terapisi uygulamalarıyla ilgili az sayıda çalışmaya rastlanmaktadır. Bu bölümde; literatür taraması sonucu sosyal hizmet alanıyla ilişkili oyun terapisi uygulamaları gözden geçirilecek ve yapılmış çalışmalara ilişkin durum ortaya konulacaktır.

Oyun terapisiyle ilgili yapılan yurt dışı çalışmalara bakıldığında, oyun terapisi uygulayıcısı ve araştırmacısı olarak sosyal hizmet uzmanların yer aldığı çalışmalara rastlanmaktadır. Fakat aynı durum ülkemizdeki çalışmalarda söz konusu değildir. Sosyal hizmet uzmanları belli eğitimleri aldıktan sonra çalıştıkları alanda oyun terapisi uygulamaları gerçekleştiriyor olsalar da; bunların araştırma kapsamında yayına dönüştürülmediği sürece konuyla ilgili bilimsel bir ilerleme ve kanıta dayalı uygulamaların gerçekleştirilemeyeceği görülmektedir.

Ülkemizde oyun terapisiyle ilgili yapılan tezlere bakıldığında; çoğunlukla psikoloji alanında yapılmıs 24 tane teze rastlanmıştır (https://tez.yok.gov.tr/UlusalTezMerkezi/tezSorguSonucYeni.jsp). Bu tezlerin 2013-2020 y1llar1 arasını kapsadığı görülmektedir. Bu durum, ülkemizde oyun terapisi alanına yönelik bilimsel ilginin yeni olduğu ve çalışmaların gelişmekte olduğunu göstermektedir.

\section{Yurt Dişı Oyun Terapisi Uygulama Örnekleri}

Oyun terapisine ihtiyaç duyulan alanların gün geçtikçe çeşitlendiğini belirten Carter (2015), koruma altındaki çocuk sayısının fazlalaştı̆ı̆ıa ve buralarda hizmet veren uzmanların oyun terapisi uygulamalarının önemine dikkat çekmiştir. Yazara göre evsizlik, stres ve çaresizlik duygularının hakim olduğu bir süreçtir. Bu noktada yetişkin-çocuk etkileşimde oyun terapisinin önemi ortaya çıkmaktadır. Çocuğun duyulduğunun, görüldüğünün ve onunla ilgilenildiğinin mesaj1 ancak bu yöntemle verilebilir. Baggerly ve Jenkins (2004)'de 5-11 yaş aralı̆̆ında barınma merkezinde yaşayan çocuklara çocuk odaklı oyun terapisi uygulamış ve ön-test, son-test değerlendirmesiyle çocukların kaygılarını ölçmüştür. 9-12 seans sonunda çocukların olumsuz duygu durumu, endişeleri üzerinde oyun terapisinin olumlu etkisi olduğunu saptamıştır (Baggerly ve Jenkins, 2009).

Sosyal hizmet uzmanı tarafindan gerçekleşen bir oyun terapisi uygulamasında; uzman, kardeş rekabeti sorunları yaşayan iki çocuğun an be an etkileşimlerini çocuk merkezli oyun terapisi yöntemini kullanarak incelemiştir (Hung ve diğ. 2019). 6 haftalık oyun terapisi seanslarını videoya kaydederek konuşma analizi yapmıştır. Seanslarındaki konuşmalara makalesinde yer veren uzman, oyun terapisi sonucunda çocukların duygularını anlayarak iç görü kazanmalarına yardımcı olduğunu belirtmiştir.

Bir başka vaka çalışmasında cinsel istismara uğrayan çocuklara yönelik oyun terapisi çalışmaları yapan sosyal hizmet uzmanlanından oluşan ekibinin deneyimlerine yer verilmektedir. Oyun seanslarına çocuklarla birlikte ebeveynlerin dahil edildiği çalışmada filial oyun terapisinin etkililiğine dikkat çekilmiştir. (Hill, 2006). Diğer bir çalışmada, travmatik bir olay yaşamış kalıcı stres tepkileri gösteren dokuz yaşındaki bir çocuğa stajyer bir terapist tarafindan uygulanan yönlendirici olmayan oyun terapisi müdahale sürecinden bahsedilmektedir (Ryan ve Needham, 2015). Çalışmada, yönlendirici olmayan oyun terapisi uygulamalarının travmatik deneyim yaşayan çocukların rehabilitasyonunda etkili olduğu görülmüsstür. Bunun yanında bağlanma problemleri olan çocuklara uygulanan oyun terapisinin de etkililiği araştırmalarda yer almaktadır (Ryan, 2004). 
Koruyucu ailelerin gözetiminde yaşayan çocukların istismar edilmesini önlemeye yönelik psikanalitik oyun terapisi yöntemiyle bir çalısma yapılmıştır. 20 çocukla oyun terapisi uygulaması gerçekleştirilmiş ve çalışma sonunda çocukların mental sağlık durumlarında istatistiksel olarak anlamlı bir iyileşme gözlenmiştir. Araştırmacı, uygulanan oyun terapisinin akran ilişkisi sorunları, kayg1, uyku problemleri, dissosiyatif belirtiler (farklı biriymiş gibi konuşma, konuşamama, bayılma, unutkanlık, kim olduğunu bilememe gibi), saldırganlık/ şiddet, depresyon gibi sorunların azalmasını sağladığını rapor etmiştir (Care ve diğ., 2014). Ayrıca koruyucu ailelerle ilgili yapılan bir başka çalışmada filial terapinin (aile terapisi ve oyun terapisi yaklaşımlarının bütünleştiği oyun terapisi türü) koruyucu aile bakımı alanında tercih edilen bir müdahale olarak uygunluğu ve ampirik temelleri açıklanmıştır (Gilmartin ve McElvaney, 2020).

Başka bir çalışmada şeker hastalığı tanısı almış insüline bağımlı çocuklardan deney ve kontrol grupları oluşturulmuştur (Jones ve Landreth, 2002). Deney grubuna 3 hafta toplam 12 seans çocuk merkezli oyun terapisi uygulanmıştır. Çalışmanın sonunda oyun terapisi alan deney grubunun, kontrol grubuna kıyasla şeker hastalığına uyumunda anlamlı bir artış saptanmıştır.

Bratton ve diğ. (2005), 1953- 2000 yılları arasında gerçekleştirilmiş 93 çalışmaya ilişkin bir meta-analiz çalışması yapmıştır. Çalışmanın sonuçları oyun terapisi müdahalesinin çocuklar üzerindeki etkisinin istatistiksel olarak anlamlı olduğunu ortaya koymuştur. Meta analiz raporu, özellikle de filial ve çocuk merkezli oyun terapisinin etkililiğini göstermektedir. Raporda istatistiksel anlamlılık düzeylerine göre oyun terapisinin okul ortamları, ayakta tedavi klinikleri, yatılı ortamlar dahil çeşitli ortamlarda etkili olduğu düşünülmektedir.

Bundan önceki çalışmalar hep yetişkin gözüyle konuya yaklaşırken başka bir çalışma, oyun terapisinin çocuk gözünden nasıl algılandığı üzerine yapılmıştır. Çalışmada çocukların oyun terapisi odasındaki vakitlerini "eğlence" olarak adlandırdıkları görülmüştür. Araştırmacı, güvenli ve sürdürülebilir bir ilişki içinde eğlenmenin çocuklar için terapötik sürecin en önemli yönü olduğunu belirtmektedir. Ayrıca, "eğer çocukları dinlemeye ilişkin yollar bulabilirsek, onların bize öğretecekleri çok şey var" ifadesini kullanmaktadır (Carroll, 2002).

\section{Türkiye'deki Oyun Terapisi Uygulama Ötnekleri}

3-10 yaş arası gelişimsel sorunu olan çocuklarda ve ebeveynlerinde filial terapinin etkisinin incelendiği yarı deneysel bir çalışma, 7 anne ve çocuğunun katılımıyla gerçekleşmiştir (Öztekin ve Gülbahçe, 2019). Ön-test ve son- test uygulamalarının olduğu çalışmada, araştırmaya kattlan annelere haftada bir gün üç saat eğitim verilmiş, ayrıca çocuklarla oyun seansları düzenlenmiştir. Çalışmanın çocukların gelişimsel problemlerinin azaltılmasında, ebeveynlerin çocuklarını kabul ve çocuklarına empati yapabilme düzeylerinin de artmasında etkili olduğu görülmüştür. Başka bir araştırmada; çocuk evlerinde kalmakta olan korunmaya muhtaç çocukların travma sonrasında ortaya çıkan stres belirtileri üzerinde gelişimsel oyun terapisinin etkisi incelenmiştir (Altun, ve diğ., 2019). Çalışmada 4-8 yaş arası 30 çocuğa oyun terapisi uygulanmıştır. Ön-test, son-testin uygulandığı çalışmada gelişimsel oyun terapisinin çocukların travma sonrası ortaya çıkan streslerini azaltmada etkili olduğu saptanmıştır.

Okul öncesi dönemde çekingenlik davranışı olan bir çocuk üzerinde oyun terapisinin etkisinin incelendiği bir araştırmada; oyun terapisi seansları sonunda ebeveyn ve öğretmenden alınan değerlendirmelere göre çocuğun duygusal sorunlarının, akran ilişkileri problemlerinin azaldığı ve sosyal uyumumun güçlendiği ortaya konmuştur (Koçkaya ve Siyez, 2017). Sınır problemi ve agresyonu olan 5 yaş 9 aylık olan bir erkek çocukla çocuk merkezli oyun terapisi odağında gerçekleşen bir çalışmada uygulamanın olumlu sonuçlar verdiği görülmüştür (Yanıt, 2020). Başka bir çalışmada, 4,5 yaşında selektif mutizm tanısı almış bir çocukla 20 seans süren yönlendirilmemiş oyun terapisi sonucunda çocuğun göz temasının arttığı, kısık sesle kendini ifade etmeye başladığ1, oyun terapisi odası dışında da çevresindeki insanlarla iletişim kurmaya başladığı saptanmıştır (Yanıt, 2019).

Kadın konukevlerinde kalan bireylerin 3-6 yaş arası çocuklarının problemli davranışlanı üzerinde oyun terapisinin etkililiğinin incelendiği deneysel bir çalışmada ön-test, son-test ve izleme ölçümleriyle 4 deney ve 4 kontrol grubundan 8 çocukla bir çalışma gerçekleştirilmiştir (Kılınç ve 
Saltık, 2020). Çalışma sonuçlarına göre çocukların hem dışa dönük saldırgan davranışları hem de korku, endişe, çekingenlik gibi içe dönük problemli davranışlarında azalma olduğu görülmüştür. Öte yandan hastane ortamlarında çocuklarla iletişim kurma ve onların yaşadıkları süreçlerle ilgili olarak duygu, düşünce ve algılarını anlamada oyunun etkisi vurgulanmaktadır. Çocuğun öfke, stres, korku, agresiflik, güvensizlik gibi duygularını anlamada; ailesi, arkadaşları ya da hastane personeli ile ilgili algılarını ortaya çıkarmada oyunun gücünden yararlanılmaktadır (Kıran, ve diğ., 2013). Bu çocuklarda oyun, skkıntılarının panzehiri olabilir (Weil, 2012).

Bulut (2008), okullarda çalışan psikolojik danışmanlanın gün geçtikçe daha fazla sayıda cinsel istismar mağduru çocukla karşılaştı̆̆ını ve bu çocuklarla çalışabilmeleri için hazırlık yapmaları gerektiğini savunmaktadır. Bu noktada uzmanlara psikodinamik yaklaşıma dayanan oyun terapisi yöntemiyle teşhis ve sağaltıma yönelik bir yol haritası sunmaktadır. Yazar, oyun terapisi uygulayacak profesyonellerin üst düzey eğitimlerden sonra bu işi yapabileceklerini vurgulamaktadır.

\section{Sosyal Hizmet Uzmanlarının Oyun Terapisi Uygulamalarındaki Yeri ve Önemi}

Sosyal hizmet uzmanları, oyun terapisi uygulamalarında en önemli ruh sağlığı profesyonelleri arasında yer almaktadır. Amerikan Oyun Terapisi Derneği (Association for Play Therapy: APT), oyun terapisi uygulayıcıları arasında ilk sırada klinik sosyal hizmet uzmanlarına yer vermiştir(https://www.youtube.com/watch?v $=4$ ovwAdxCs0\&ab channel=AssociationforPlayTh erapy). Belirtilen listede klinik sosyal hizmet uzmanlarının dışında, psikolojik danışmanlar, aile ve evlilik terapistleri, psikologlar, okul danışmanları/psikologları, pediatristler ve psikiyatrik hemşireler oyun terapisi uygulayıcıları olarak sıralanmıştır. Bunun dışında birçok oyun terapisi derneği, üyelerinin psikolojik danışman, sosyal hizmet uzmanı, psikolog, psikiyatrist ve aile terapisti gibi profesyonellerden oluştuğunu belirtmiştir (Tayvan Oyun Terapisi Derneği (ATPT), Kanada Çocuk ve Oyun Terapisi Derneği (CACPT), İngiliz Oyun Terapistleri Derneği (BAPT) ve Avustralya Pasifik Oyun Terapisi Derneği (APPTA)) (Tsai, 2013)

Oyun terapisi uygulayacak profesyonellerin akredite olmuş bir kurumdan oyun terapisi teorik ve süpervizyon eğitimlerini almaları, literatürde ve uygulamalarda vurgulanan ortak noktadır. Oyun terapisi sihirli bir değnekle çocukta değişim ve gelişim yaratmak değildir. Profesyonellerin önemli derecede bilgiye, eğitime, süpervizyona, danışmanlığa/konsültasyona, farkındalı̆ga, kişisel yatırıma, becerilere ve çocukların gelişimine olan inanca ihtiyaçları vardır (Ray, 2019: 17). Dolayısıyla sosyal hizmet uzmanlarının da belirtilen eğitimlerle konuya ilişkin bilgi, beceri ve donanıma sahip olması önem arz etmektedir.

Sosyal hizmet uzmanları, oyun terapisi uygulamalarında ön sırada belirtilse de oyun terapisi uygulayıcısı olarak sayılarının çok az olduğu bilinen bir başka gerçektir. Yapılan bir çalışmada APT ve Amerikan Danışmanlık Derneği (American Counseling Association: ACA)'ne üye olan çeşitli profesyonellerin sayılarına ulaşılmıştır. Sonuçlara göre bu derneklere üye olan profesyonellerin yaklaşık \% 20'sinin sosyal hizmet uzmanı olduğu raporlanmıştır (Lambert ve diğ.., 2007). Oysaki çalışma alanları göz önüne alındığında uzmanların istismara uğramış, travma yaşamış, kurum bakımına yerleşmiş, okulda uyum sorunları yaşayan, anne- babasının boşanma sürecinin ortasında kalan, sığınmacı olarak bir başka ülkeye gelen, suça sürüklenmiş, davranım bozukluğu gösteren ya da onkoloji kliniklerinde tedavi gören ve daha birçok alanda her an çocukla teması söz konusudur. Bu hassas çalışma gruplarına müdahalede çocuğun sorunları ve kaygılarıyla çalışırken en etkili yöntem olarak önerilen oyun terapisini kullanan sosyal hizmet uzmanlarının sayısının ve niteliğinin artması dikkate değer bir konudur (Webb, 2017: 194). Zira uzmanların müdahale çantalarında oyun terapisi bilgisi ve eğitimi yoksa ve bunu çocukla çalışmada araç olarak kullanamıyorsa yaptığı çalışmanın etkililiğini sorgulamak gerekecektir. Çünkü yukarıda da belirtildiği gibi çocukla çalş̧ma, yetişkinle çalışmadan farklı özel bilgi, beceri ve yöntemleri gerektirmekte ve oyun terapisi etkililiği kanıtlanmış en önemli yöntem olarak bilinmektedir.

Sosyal hizmet uzmanlarının çocuklarla oyun terapisi kullanımına ilişkin algılarının incelendiği bir çalışmada, katıllımcıların \%90'ının oyun terapisinin etkili bir müdahale biçimi olduğunu kabul etmesine rağmen, sadece $\% 31$ 'inin müracaatçılara yönelik oyun terapisini kullandığını görülmüştür. Ayrıca bu çalışmada, katılımcıların büyük çoğunluğu lisansüstü eğitimleri ya da sürekli eğitim 
çalışmaları boyunca oyun terapisini ders olarak çok az gördüklerini belirtmişlerdir. Bu konuda eğitim alamamıs olmalarına rağmen katılımcıların \% 63'ü tüm sosyal hizmet uzmanlarının temel oyun terapisi becerileri konusunda eğitim alması gerektiği konusunda hemfikir olmuşlardır. (Weil, 2012). Ülkemizde oyun terapisi uygulayıcısı olan sosyal hizmet uzmanlarının sayılariyla ilgili istatistiki bir araştırma söz konusu değildir. Kendini bu alanda geliştiren, eğitimlere katılan bazı uzmanların çalıştıkları kurumlarda ya da özel danışma merkezlerinde oyun terapisi uygulamalanı söz konusu olsa da bu uzmanların sayı ve nitelikleriyle ilgili yapılmış bir bilimsel çalışma yoktur.

Ülkemizdeki mevcut oyun terapisi eğitimlerine de bakıldığında akredite olmuş eğitim sisteminin olmadığ1 görülmektedir. Bu konuda Amerikan Oyun Terapisi Derneği (Association for Play Therapy: APT)'nin uygulamalarına bakıldığında eğitimini tamamlamış derneğe üye olan terapistlerin danışma, araştırma, akademik yayınlara erişim, konferans, çalıştay, süpervizyon, profesyonellerin birbirleriyle etkileşimi vb. firsatlardan yararlandığı görülmektedir. Ayrıca dernek, üniversitelerle işbirliği halinde akredite programlar düzenlemektedir. https://www.youtube.com/watch?v=_4ovwAdxCs0\&ab_channel=AssociationforPlayTherapy.

Diğer taraftan sosyal hizmet uzmanlarıyla yapılan bir çalışma, katılımcıların \% 69'unun oyun terapisi uygulamadığını çünkü bunu yapmak için kendilerini yeterince eğitimli hissetmediklerini ortaya koymuştur. Ek olarak, yapılan çalışmada ankete katılanların yaklaşık \% 73'ü oyun terapisinde lisansüstü dersleri olmadığını ve \% 66'sının oyun terapisinde sürekli eğitim almadı̆̆ını belirtmiştir (Weil, 2012). Bu veriler, sosyal hizmet uzmanlarının eğitimsel ve profesyonel alanda oyun terapisi eğitimi ile karşılaşmalarında büyük bir boşluk olduğunu göstermektedir. Bu durum ülkemiz için de geçerlidir; çok az sayıda üniversitede sosyal hizmet lisans ve lisansüstü programlarında oyun terapisiyle ilgili derslere yer verilmektedir.

Bu noktada sosyal hizmet alanında konuyla ilgili akademisyenlerin de oyun terapisiyle ilgili çalışmalarını artırmaları ve eğitim sistemi içerisine dersler yerleştirmeleri önem arz etmektedir. Farley ve ark. (2020) profesyonellere aile müdahalelerini kapsayan oyun terapisi uygulamalaryyla ilgili daha ileri düzey eğitimlerin ve süpervizyonun verilmesi gerektiğini belirtmektedirler. Bu amaçla klinik sosyal hizmet programlarında konuyla ilgili teorik ve pratik derslerin sağlanması gerektiği vurgulanmaktadır (Farley ve diğ., 2020). Konuya öneri getiren Weil (2012), üniversitelerde oyun terapisi eğitiminin sosyal hizmet müfredatında yaygınlaşmasıyla öğrencilerin bilgi temelinin ve oyun terapisi uygulayabilen uzmanların sayısının artırlabileceğini belirtmektedir. Bunun yanında verilen eğitimlerle öğrencilerde konuya ilişkin ilgi ve farkındalık oluşacağı; böylelikle öğrencileri oyun terapisinin etkililiğini destekleyen araştırmaların yaygınlaştırılması konusunda teşvik edebileceğini ifade etmektedir.

Ülkemizde, sosyal hizmet uygulamalarında oyun terapisine dikkat çeken sayılı yayınlardan biri olan Aykara'(2017) nın “Çocuk Merkezli Oyun Terapisinin Engelli Çocuklara Yönelik Sosyal Hizmet Uygulamaları Açısından Önemi” başlıklı çalışmasında sosyal hizmet uzmanlarının çocuklarla iletişim kurmayı kolaylaştırması bakımından çocuk merkezli oyun terapisine ilişkin bilgi ve becerilere sahip olmalarının, sosyal hizmet uzmanlarının çalışmalarının etkililiğini artıracağı belirtilmektedir. Ayrıca, oyun ve oyun terapisine ilişkin genel bilgilerin verildiği bir çalışma da çocukla çalışmada oyunun önemine dikkat çekilmiştir (Öztürk, 2014).

Çocuklarla çalışan ve çocuklarla sosyal hizmet uygulaması kitabını yazan Webb (2017), kendi uygulama örneklerini anlattı̆̆ kitabında çocukla çalışırken, "resim çizme, cümle tamamlama" gibi tekniklerden yararlandığını ve "Oyun terapisi” uygulamaları gerçekleştirdiğini belirtmektedir (Webb, 2017: 104, 108, 214). Kitabında farklı sorunlar yaşayan çocuklarla bu yöntemleri kullanarak nasıl çalıştığına ve müdahale sonuçlarına yer veren yazar, konu ile ilgili önemli bir örnek teşkil etmektedir. Benzer şekilde çalışmış oldukları vaka örneklerinden oluşan kitapları Türkçe’ye çevrilmiş oyun terapistleri mevcuttur (Axline, 2018, 2019; Ray, 2019) Bu çalışmaların oyun terapisi uygulama ve araştırmalarının gelişimi için önemli olduğu görülmektedir.

Bu noktada Axline (2019)'nın Oyun Terapisi kitabındaki bir örnek, sosyal hizmet alanında oyun terapisinin önemine bir kez daha dikkat çekmektedir. Kurum bakımındaki bir çocuk, annesinin onu almak ve bir yerlere götürmek için söz verdiği günlerde, sabırsızlıkla onu kapıda 
beklemekte; fakat anne sözünü tutmamakta ve çocuğu hayal kırıklığına uğratmaktadır. Arkadaşlarının alay konusu haline gelen çocuk, günlerce yemek yememekte, uyumamakta, hislerini konuşamamakta, hastalanarak hastaneye kaldırılmaktadır. Yaşadığı hayal kırıklığını ifade edemeyen ve bu semptomları geliştiren çocuğun duygu ve düşüncelerini aktarabilmesi için oyun terapisinin vazgeçilmez bir kaynak olacağı aşikardır. Bu ve benzeri birçok vaka için çalıştkları kurumlarda sosyal hizmet uzmanlarının oyun terapisi uygulamaları önem arz etmektedir.

Görüldüğü gibi oyun terapisinin çocuklarla sosyal hizmet uygulamasında etkili bir müdahale şekli olduğu gerçeği giderek daha fazla üzerinde durulan bir konu olmuştur. $\mathrm{Bu}$ nedenle müdahalelerinde kanıta dayalı uygulamaları benimseyen sosyal hizmet uzmanları için oyun terapisi geçerli, uygulanabilir bir yöntem olarak görülmektedir. Bu açıdan bakıldığında çocuklarla sosyal hizmet uygulamasında ampirik temellere dayalı, kanıtlanmış en iyi müdahale yöntemlerinin kullanılmasının sosyal hizmet uygulamasının etkililiği için bir gereklilik olduğu, bunun ise oyun terapisi yöntemleriyle mümkün olabileceği belirtilmektedir (Weil, 2012). Uzmanlar aynı zamanda kendi uygulamalarını araştırmalara dönüştürüp literatüre katkı sağlayarak gelecek çalışmalara sşık tutabilirler.

\section{Sonuç ve Öneriler}

Oyun çocuğun dili, oyuncaklar ise kelimeleridir. Montaigne’e göre oyun, çocukların en gerçek uğraşıdır ve yetişkinlerin işe gitmesi gibi onlarda oyuna gider. Bu sebepledir ki çocukları anlamak, duymak, görmek, yaşadıklarını hissetmek ve onlara yardımcı olmak isteniliyorsa çocuklarla çalsşan bir profesyonel için oyun terapisi vazgeçilmez bir kaynaktır. Oyun terapisi, çocuklarla çalışırken kullanılabilecek etkililiği araştırmalarla kanıtlanımış en önemli yöntem olarak kabul edilmektedir. Uygulamalarında sıkça çocukla temas eden, çoğunlukla da hassas gruplarla çalışan, onların hayatlarına dokunan sosyal hizmet uzmanlarının çalışmalarında oyun terapisini kullanmalarının gerekliliği literatür ve yapılan araştırmalar sonucu bilinen bir gerçek olmuştur. Mevcut durumda bu yöntemi kullanan uzmanlar söz konusu olsa da uygulamaların yaygınlaştırılması ve sistematik bir şekilde sürdürülmesi önem arz etmektedir. Bu çalışmanın sosyal hizmette oyun terapisi uygulamalarına dikkat çekmek ve konunun önemini ortaya koymak açısından farkındalık yarattığ1 ve literatüre katkı sağladığ1 düşünülmektedir. Konuyla ilgili yapılacak gelecek araştırmalara ışık tutacağı düşünülmektedir. Bu noktada çalışmadan çıkan sonuçlar 1şığında bazı öneriler sunulmuştur:

- Üniversitelerin sosyal hizmet bölümlerinin lisans ve lisansüstü eğitimlerinde oyun terapisine yönelik dersler müfredata eklenmeli ve yaygınlaştırılmalıdır.

- Ülkemizdeki mevcut oyun terapisi eğitimlerinin uluslararası koşullara uygun standartları oluşturulmalı ve akreditasyonları sağlanmalıdır.

- Gerekli eğitimleri alarak oyun terapisi uygulamaya başlayan uzmanlara süpervizyon desteği sağlanmalı, konferans ve çalıştaylarla uzmanların yaşam boyu öğrenme süreçleri desteklenmelidir.

- Sosyal hizmet literatüründe konuyla ilgili çok az çalışma olduğu görüldügünden oyun terapisinin etkililiğini ortaya koyan çalışmalara ihtiyaç söz konusudur. Sosyal hizmet uzmanlarının oyun terapisi uygulamalarıyla ilgili bilimsel araştırmalar planlanmalı ve bunlar yayınlanmalıdır. Bu noktada üniversitelerle işbirliği sağlanmalı araştırma ve uygulama arasında bir köprü oluşturularak kanıta dayalı uygulamaların yaygınlaştırılması sağlanmalıdır.

- Ülkemizde sosyal hizmet uzmanlarının oyun terapisi yöntemini uygulamalarında kullanma konusuna ilisskin istatistiki verilere dayanan bir bilimsel yayın yoktur; bu nedenle konuyla ilgili bir araştırma planlanmalı ve mevcut durum ortaya konmalıdır.

- Oyun terapisiyle ilgili üst kurum ve kuruluşlar, dernekler oluşturulmalıdır. 


\section{Kaynakça}

Altun, K., Demir, V., Ünübol, H. (2019). Gelişimsel Oyun Terapisinin Çocuk Evlerinde Kalmakta Olan 4-8 Yaş Grubu Çocukların Travma Sonrası Duygusal Streslerine Olan Etkileri. Uluslararast Sosyal Bilimler Dergisi, 2(2), 35-46.

Axline, V. M. (2018). Benliğini Arayan Cocuk (Çev: Misli Baydoğan). Ankara: Panama yay.

Axline, V. M. (2019). Oyun Terapisi (Çev: Misli Baydoğan). Ankara: Panama yay.

Aykara, A. (2017). Çocuk Merkezli Oyun Terapisinin Engelli Çocuklara Yönelik Sosyal Hizmet Uygulamaları Açısından Önemi. Toplum ve Sosyal Hižmet, 28(1), 169-186.

Baggerly, J., Jenkins, W. W. (2009). The effectiveness of child-centered play therapy on developmental and diagnostic factors in children who are homeless. International Journal of Play Therapy, 18(1), 45-55.

Bratton, S. C., Ray, D., Rhine, T., Jones, L. (2005). The Efficacy of Play Therapy With Children : A Meta-Analytic Review of Treatment Outcomes. Professional Psychology Research and Practice, 36(4), 376-390. https://doi.org/10.1037/0735-7028.36.4.376

Bulut, S. (2008). Erken Çocukluk Dönemi Cinsel İstismarının Psikodinamik Oyun Terapisiyle Teşhisi Ve Tedavisi. Türk Psikolojik Danısma ve Rebberlik Dergisi, 3(29), 131-144.

Care, F., Clausen, J. M., Ruff, S. C. (2014). For As Long As It Takes : Relationship-Based Play Therapy for For As Long As It Takes: Relationship-Based Play Therapy for Children in Foster Care. Psychoanalytic Social Work, 19(May), 43-53. https://doi.org/10.1080/15228878.2012.666481

Carroll, J. (2002). Play therapy : the children's views Correspondence : Child and Family Social Work, 7, 177-187.

Carter, A. W. (2015). Equipping Homeless Shelter Providers With Child- Centered Play Therapy Skills With Child-Centered Play Therapy Skills. Journal of Poverty, 19(4), 399-408. https://doi.org/10.1080/10875549.2014.999973

Center For Clinical Social Work. (2007). Practice with Children and Their Families: A Specialty of Clinical Social Work.

Farley, J., Whipple, E., Riebschleger, J. (2020). Social Work in Mental Health Integrating play therapy into early childhood mental health treatment services: clinician and parent perspectives. Social Work in Mental Health, 18(3), 331-348. https://doi.org/10.1080/15332985.2020.1742851

G. Cooper, M., Granucci Lesser, J. (2011). Clinical Social Work Practice. Pearson.

Gilmartin, D., McElvaney, R. (2020). Filial Therapy as a Core Intervention with Children. Child Abuse Review, 29, 159-166. https://doi.org/10.1002/car.2602

Hill, A. (2006). Play therapy with sexually abused children: Including parents Correspondence: Child and Family Social Work, 11, 316-324. https://doi.org/10.1111/j.13652206.2006.00411.x

Hung, E. N., Leung, G. S., Cheung, J. C. (2019). Responding to children ' s ' emotion talk ': a conversation analysis of a therapeutic encounter between a social worker and two siblings using child-centred play therapy. Journal of Social Work Practice, 33(4), 433-445. https://doi.org/10.1080/02650533.2019.1686349

IFSW (International Federation of Social Workers) (2014). Global definition of social work. http://ifsw.org/policies/definition-of-socialwork/ Erişim: 20.01.2019

Jones, E. M., Landreth, G. (2002). The efficacy of intensive individual play therapy for chronically ill children. International Journal of Play Therapy, 11(1), 117-140.

Kılınç, F. E., Saltık, N. (2020). Kadın Konukevlerinde Kalan Çocukların Problem Davranışları Üzerinde Oyun Terapisinin Etkisinin İncelenmesi. ACU Sağhle Bil. Dergisi, 11(1), 27-34.

Kıran, B., Çalık, C., Esenay, I. F. (2013). Terapotik Oyun: Hasta Çocuk İle İletişimin Anahtarı. Ankara Sağhk Bilimleri Dergisi, 2((1-2-3)), 1-10. 
Kılıç Ceyhan, E. (2020). Çocuklarla sosyal hizmet uygulamasında oyun terapisinin önemi. Journal of Human Sciences, 17(4), 1137-1148. doi:10.14687/jhs.v17i4.6083

Knell, M. S. (2017). Bilişsel Davranış̧̧ı Oyun Terapisi. Oyun Terapisinin Temelleri (Çev: Banu Tortamiş Özkaya), 313-328. Ankara: Nobel Yay.

Koçkaya, S., Siyez, M. D. (2017). Okul Öncesi Çocuklarının Çekingenlik Davranışları Üzerine Oyun Terapisi Uygulamalarının Etkisi. Psikiyatride Güncel Yaklassmlar, 9(1), 31-44.

Lambert, F. S., LeBlanc, M., Mullen, A. J., Ray, D., Baggerly, J., White, J., Kaplan, D. (2007). Learning More About Those Who Play in Session: The National Play Therapy in Counseling Practices Project (Phase I). Journal of Counselling and Development, 85(1), 42-46.

Landreth, G. L. (2002). Play therapy: The art of the relationship. New York: NY: Brunner-Routledge.

Nash B., J., Schaefer, C. (2017). Oyun TerapisiTemel Kavramlar ve Uygulamalar. Oyun Terapisinin Temelleri (Çev: Banu Tortamıs Özkaya, 3-15). Ankara: Nobel Yay.

Norton, C. C., Norton, E. B. (2017). Deneyimsel Oyun Terapisi. Oyun Terapisinin Temelleri (Çev: Banu Tortamış Özkaya), 187-203, Ankara: Nobel Yay.

Öğretir, D.A. (2008). Oyun ve Oyun Terapisi, Gazi Üniversitesi Endüstriyel Sanatlar Eğgitim Fakültesi Dergisi, 22: 94-100

Öztekin, G. G., Gülbahçe, A. (2019). 3-10 Yaş Arası Gelişimsel Problemleri Olan Çocuklarda Ve Ebeveynlerinde Filial Terapinin Etkisinin İncelenmesi. Uluslararası Türkse Edebiyat Kültür Eğitim Dergisi, 8(4), 2322-2340.

Öztürk, B.A. (2014). Çocukla Çalışmada Oyun. Prof.Dr. Gönül Erkean'a Armağan, Sosyal Hį̧met ve Mülakat, Ed: Prof.Dr. Vedat Işıkhan, Sosyal Hizmet araştırma, uygulama, geliştirme derneği yay. 214-221

Ray, C. D. (2019). İleri Dürey Oyun Terapisi. (Ç. editörü: B. E. Bakay, Çev: Duygu Olgaç). İstanbul: Pinhan yay.

Rennie, R., Landreth, G. (2000). Effects of filial therapy on parent and child behaviors. International Journal of Play Therapy, 9(2), 19-37.

Ryan, V. (2004). Adapting Non-directive Play Therapy for Children with Attachment Disorders, 9(200401), 75-87. https://doi.org/10.1177/1359104504039174

Ryan, V., Needham, C. (2015). Non-directive Play Therapy with Children Experiencing Psychic Trauma. Clinical Child Psychology and Psychiatry, 6(200107), 437-453.

Topham, L. G., VanFleet, R. (2011). Filial Therapy: A Structured and Straightforward Approach to Including Young Children in Family Therapy. The Australian And New Zealand Journal Of Famuly Therapy, 32(2), 144-158. https://doi.org/10.1375/anft.32.2.144

Tsai, M. (2013). Children and Youth Services Review Research in play therapy: A 10-year review in Taiwan. Children and Youth Services Review, 35(1), 25-32. https://doi.org/10.1016/j.childyouth.2012.10.016

Webb, B. N. (2017). Cocuklarla Sosyal Hiæmet Uygulamasi, (Çev ed: Ercüment Erbay) Nika yay. Ankara.

Weil, S. (2012). Social Workers 'Role in the Delivery of Play Therapy to Children. St. Catherine University.

Yanıt, E. (2019). Selektif mutizm vakasının yönlendirilmemiş oyun terapisi teknikleri ile sağaltımı (Olgu sunumu). Türkiye Bütüncül Psikoterapi Dergisi, 2(3), 68-76.

Yanıt, E. (2020). “Çocuğumu Benden Alın!’Sınır Koyma Probleminin Çocuk Merkezli Oyun Terapisi İle Sağaltımı (Olgu Sunumu)*. Türkijye Bütüncül Psikoterapi Dergisi, 3(5), 35-48.

https://www.thekidstherapycenter.com/about-us

https://www.youtube.com/watch?v = 4ovwAdxCs0\&ab channel=AssociationforPlayTherapy

(https://tez.yok.gov.tr/UlusalTezMerkezi/tezSorguSonucYeni.jsp). 


\section{Extended English Summary}

If we can find ways to hear and understand children, they have a lot to say, tell and teach us, adults. Children who do not have extensive verbal abilities like adults can express themselves through playing. It has been proven by research that the best method by which they can convey their feelings, thoughts and problems is play therapy. Play therapy is a method offered by a trained play therapist that focuses on expressing children's needs through plays and toys. Play therapy applications take place in various forms due to their basis in different theories and methodologies. Some of the commonly used and proven effective forms are: child-centered play therapy, experiential play therapy, cognitive behavioral play therapy, filial therapy.

At this point, it is important that professionals working with children are equipped with the knowledge of play therapy. Social workers who frequently come into contact with children in their professional lives should be involved in the field as play therapy practitioners. However, when the literature is examined, it is seen that there are very few practices and studies on the subject in Turkey. Considering the international studies on play therapy, we can see studies involving social workers as play therapy practitioners and researchers. But we cant see enough attention in our country. Although social workers perform play therapy practices in their field after receiving certain training; it is seen that scientific progress and evidence-based practices cannot be achieved unless there are researches and published articles.

Although social workers are at the forefront of play therapy practices, it is another known fact that they are very few in number as play therapy practitioners. However, considering their fields of work, experts always have contact with children (who are abused, traumatized, settled in institutional care, experiencing adjustment problems at school, staying in the middle of her parents' divorce process, coming to another country as an asylum seeker, driven to crime, having behavioral disorders or being treated in oncology clinics and many more). It is noteworthy that the number and quality of social workers using play therapy, which is recommended as the most effective method when dealing with the problems and concerns of children, has increased in intervening in these sensitive groups. Because if experts do not have the knowledge and training of play therapy in their interventions and cannot use it as a tool in working with children; it is necessary to question the effectiveness of their work. Because working with children requires special knowledge, skills and methods different from working with adults and play therapy is known as the most important method with proven effectiveness.

The common point emphasized in the literature and practices is that professionals who will apply play therapy should receive play therapy theoretical training and supervision from an accredited institution. Play therapy is not a magic wand which can create change and development in children immediately. Professionals need substantial knowledge, training, supervision, consultation, awareness, personal investment, skills on the issue and should have a belief in children's development (Ray, 2019). Therefore, it is important that social workers have the knowledge, skills and equipment related to the subject with the play therapy training.

Considering the existing play therapy training in our country, it is seen that there is no accredited education system. In addition, very few universities offer courses on play therapy in social work undergraduate and graduate programs. Looking at the applications of APT (Association for Play Therapy) in this regard; It is observed that the therapists who are members of the association, who have completed their education, benefit from opportunities such as consultation, research, access to academic publications, conferences, workshops, supervision, and interaction between professionals.

The fact that play therapy is an effective form of intervention in social work practice with children has increasingly been emphasized. For this reason, play therapy is seen as a valid and applicable method for social workers who adopt evidence-based practices in their interventions. From this point of view, it is stated that the use of the best proven intervention methods based on 
empirical grounds in social work practice with children is a necessity for the effectiveness of social work practice, and this can be possible with play therapy methods.

This study presents the place and importance of play therapy in social work practice with children in the light of the researches and applications in the literature, and highlights the importance of the use of play therapy as a method by social workers working with children. It has been observed that play therapy needs a wider coverage in social work practice and research. Suggestions have been made for popularizing play therapy in the relevant social work education, research and practices. Courses on play therapy should be added to the curriculum in undergraduate and postgraduate education of social work departments of universities. Standards and accreditations of the existing play therapy trainings in our country should be established in accordance with international conditions. Supervision support should be provided to experts who start to practice play therapy by taking the necessary training. Lifelong learning processes of experts should be supported by conferences and workshops. Since there are very few studies on the subject in the social work literature, there is a need for studies demonstrating the effectiveness of play therapy. Scientific research on play therapy practices of social workers should be planned and published. At this point, cooperation should be established with universities, and evidence-based practices should be disseminated by creating a bridge between research and practice. In our country, there is no scientific publication authority based on empiric data regarding the use of play therapy method by social workers in their practice. Therefore, a research on the subject should be planned and the current situation should be revealed. Top institutions and organizations and associations related to play therapy should be established. 